\title{
REVIEW
}

\section{Sexual health outcome measures for individuals with a spinal cord injury: a systematic review}

\author{
CE Abramson ${ }^{1}$, KE McBride ${ }^{2,3}$, KJ Konnyu ${ }^{4,5}$, SL Elliott ${ }^{2,4,6}$ and the SCIRE Research Team \\ ${ }^{1}$ Vancouver Coastal Health Research Institute, Vancouver Coastal Health, Vancouver, British Columbia, Canada; ${ }^{2}$ Sexual Health \\ Rehabilitation Service, GF Strong Rehabilitation Centre, Vancouver Coastal Health, Vancouver, British Columbia, Canada; \\ ${ }^{3}$ Department of Psychiatry, Faculty of Medicine, University of British Columbia, British Columbia, Canada; ${ }^{4}$ International \\ Collaboration on Repair Discoveries, Vancouver, British Columbia, Canada; ${ }^{5}$ Department of Physical Therapy, University \\ of British Columbia, British Columbia, Canada and ${ }^{6}$ Departments of Psychiatry and Urology, Faculty of Medicine, \\ University of British Columbia, British Columbia, Canada
}

Study Design: A systematic review of all sexual health outcome measures reporting psychometric properties for a spinal cord injury $(\mathrm{SCl})$ population.

Objectives: To evaluate the psychometric evidence for sexual health outcome measures used in a $\mathrm{SCl}$ population in order to (1) determine the clinical relevance of current tools and (2) suggest recommendations for future tool development.

Setting: Vancouver, British Columbia, Canada.

Methods: Electronic databases were searched for articles reporting psychometric properties of sexual health outcome measures used in a $\mathrm{SCl}$ population. The search was limited to papers published between January 1986 and January 2006. Hand-searching the references of papers obtained from the electronic search identified additional articles.

Results: Four outcome measures met the search criteria: Emotional Quality of the Relationship Scale (EQR), Sexual Activity and Satisfaction Scale (SAS), Sexual Attitude and Information Questionnaire (SAIQ) and Sexual Interest and Satisfaction Scale (SIS). While the clinical utility of these tools may be compromised by their limited scope and advancing age, they may still prove useful for guiding $\mathrm{SCl}$ research and clinical practice.

Conclusion: There is no clinically agreed upon SCI measurement tool for sexual health outcomes. To adequately assess the complex issue of sexual health, it is recommended that future sexual health outcome measures include both quantitative and qualitative data as well as address several key issues. Spinal Cord (2008) 46, 320-324; doi:10.1038/sj.sc.3102136; published online 16 October 2007

Keywords: sexual health; outcome measures; spinal cord injury; psychometric properties

\section{Introduction}

Regaining sexual function ranks as a top priority for persons with spinal cord injury (SCI). ${ }^{1}$ Individuals with SCI perceive that improved sexual function would significantly enhance their quality of life. ${ }^{2}$ Satisfaction with sexual life in general for persons with SCI remains low. ${ }^{3,4}$ Sexual concerns cited by women with SCI include problems associated with urinary and bowel accidents, not satisfying a partner, coping emotionally with changes in sexual functioning and helping a partner cope emotionally with sexual activity limitations. ${ }^{5}$ The highest ranked sexual concerns for men include methods and techniques to achieve sexual satisfaction,

Correspondence: KJ Konnyu, Research Lab, GF Strong Rehabilitation Centre, 4255 Laurel Street, Vancouver BC, Canada V5Z 2G9.

E-mail: kristinkonnyu@gmail.com

Received 19 July 2007; revised 3 September 2007; accepted 7 September 2007; published online 16 October 2007 helping a partner cope emotionally with limitations on sexual activity and ability to have children. ${ }^{6}$ Despite these findings, sexual health is one of the areas least likely to be addressed as part of a person's long-term SCI rehabilitation. ${ }^{7,8}$ For women, sexual counseling seems to occur less frequently ${ }^{9,10}$ than for men. ${ }^{11}$

The determinants of optimal sexual health for persons with SCI remain largely anecdotal, and thus poorly reproducible. Measuring sexual health outcomes is important if clinicians are to effectively evaluate interventions, achieve best practice standards and, thereby, improve quality of life for individuals with SCI. However, measuring outcomes is not enough, if the measurement tool itself does not adequately assess the phenomenon of interest. Psychometric properties (validity, reliability, responsiveness) are important in determining the degree to which the results of a tool can be trusted to represent the reality for which they are 
promulgated to measure. The purpose of this review is to offer a systematic assessment of published, psychometrically assessed sexual health outcome measures used in a SCI population, such that the clinical relevance of each measure can be determined, and recommendations for future tool development can be suggested.

\section{Methods}

This review of sexual health outcome measures was part of a broader systematic review of all outcome measures used in a SCI population. ${ }^{12}$ Several electronic databases (PubMed, MEDLINE, CINAHL, EMBASE, HaPI, PsycINFO and SportDiscus) were searched for papers reporting psychometric properties of outcome measures used in a SCI population. The search phrase 'spinal cord injury' was used in each database, while the following terms varied depending on the database searched: validation studies, instrument validation, external validity, internal validity, criterion-related validity, concurrent validity, discriminant validity, content validity, face validity, predictive validity, reliability, inter-rater reliability, intra-rater reliability, test-retest reliability, reproducibility, responsiveness, sensitivity to change, evidence-based medicine, outcome measures, clinical assessment tools, scales and measures. The search was limited to papers published between January 1986 and January 2006. References of captured articles were searched and relevant articles were pulled. All sexual health outcome measures with published psychometric properties assessed in a SCI population were reviewed and detailed information, including reliability, validity and responsiveness coefficients, was collected.

\section{Results}

Six sexual health outcome measures met the search criteria. ${ }^{13-18}$ Upon further review, two outcome measures were excluded $^{17,18}$ as the reported psychometric properties were from partners of persons with a SCI, not SCI individuals themselves. Characteristics of reviewed sexual health outcome measures are detailed in Table 1 . Reliability, validity and responsiveness findings for the tools are detailed in Tables 2-4, respectively. It should be noted that for the purpose of this paper, scales were reviewed as stand-alone tools, however two of the four tools (EQR and SAS) are part of a larger 80-item questionnaire. By evaluating these tools apart from their intended context the original intent and richness of data collected may be lost. A clinical summary of each scale follows.

\section{Emotional Quality of the Relationship Scale}

The Emotional Quality of the Relationship Scale (EQR) is a seven-item, self-report tool, which collects data that are subjective and relevant only to those in a relationship. ${ }^{13}$ The EQR measures feelings of affection and intimacy, ability to solve problems within the relationship, ability to communicate about sex with one's partner and satisfaction with these areas and the relationship as a whole. This tool forms part of an 80-item questionnaire that addresses experiences concern- ing sexual functioning, desire, and activity, sexual behavior, satisfaction with sex life and aspects of the emotional quality of the relationship. The absence of responsiveness data limits the utility of the scale to measure changes after intervention. Due to the lack of current literature using this tool, additional qualitative data collection methods such as the client interview should be used in conjunction with this scale.

Sexual Activity and Satisfaction Scale

The Sexual Activity and Satisfaction Scale (SAS) is a threeitem, self-report tool used to investigate the sexual activity, sexual desire and sexual satisfaction of individuals with SCI. ${ }^{13}$ This tool also forms part of the previously described 80-item questionnaire to which the EQR belongs. The SAS may be clinically useful to assist in understanding, describing and quantifying the sexual activity and satisfaction of individuals with SCI and may also provide a platform from which to explore issues of sexuality.

\section{Sexual Attitude and Information Questionnaire}

The Sexual Attitude and Information Questionnaire (SAIQ) evaluates the effectiveness of counseling programs and sexual education for persons with SCI and their partners. ${ }^{14,15}$ To this end, it serves as a useful tool for clinicians and it may also be useful for identifying those who would benefit from such counseling and education programs. This self-report questionnaire consists of four scales and one overall item: (I) Sexual Information, (II) Sexual Behavior Acceptability, (III) Sexual Concerns, (IV) Non-Sexual Concerns and an overall rating of one's ability to have a satisfying sexual relationship. This questionnaire may require some updating as more information has become available, not only about SCI, but also about SCI and sexuality since the publication of SAIQ in 1980.

\section{Sexual Interest and Satisfaction Scale}

The Sexual Interest and Satisfaction Scale (SIS) is a sevenitem scale, designed to measure sexual adjustment after SCI. ${ }^{16}$ The SIS provides a reasonably well-defined spinal cord specific measure that may be useful in eliciting information regarding a sensitive topic of discussion. Although it has not been widely used and psychometric properties have only been reported in one study, it is one of the few sexuality scales that has been used within the SCI population. When comparing pre- and post-injury results, one must consider the amount of time that has elapsed since injury, as injury duration affects sexual function and satisfaction. The SIS focuses on gathering subjective data of sexual interest and satisfaction and relies on the individual's memories of what life was like prior to the SCI. Lack of depth and breadth of items limits its usefulness in terms of implications for clinical practice. In application of this tool, however, researchers utilized a combined 'questionnaire-interview technique' to collect information about various aspects of sexuality as well as to check accuracy of data and allow subjects to elaborate on their answers; a method that effectively permitted an exploration of the reasons behind decline of sexual satisfaction, such as loss of sensation and motility, orgasmic problems and lowered self-esteem. 
Table 1 Sexual health outcome measure characteristics — spinal cord injury population

\begin{tabular}{|c|c|c|c|}
\hline Outcome measure & Construct measured & Items & Item response scale \\
\hline $\mathrm{EQR}^{13}$ & Emotional intimacy, affection, and communication & 7 & 4-point rating (range:4-1) \\
\hline $\mathrm{SAIQ}^{14,15}$ & $\begin{array}{l}\text { Sexual information, sexual behavior acceptability, sexual } \\
\text { concerns, and non-sexual concerns }\end{array}$ & 38 & 6-point rating (range:1-6) \\
\hline $\mathrm{SAS}^{13}$ & Sexual activity sexual satisfaction & 3 & $\begin{array}{l}1 \mathrm{Q}: \text { 3-point rating (range:3-1), } 1 \text { Q: 5-point rating } \\
\text { (range:5-1), } 1 \text { Q: 8-point rating (range:8-1, } 1 \text { Q: 8-point } \\
\text { rating (range:8-1), 2: Q 4-point rating (range:4-1) }\end{array}$ \\
\hline $\operatorname{SIS}^{16}$ & Sexual adjustment - sexuality and sexual function & 7 & $4-$ point rating (range:3-0) \\
\hline
\end{tabular}

Abbreviations: Q, question; EQR, Emotional Quality of the Relationship Scale; SAIQ, Sexual Attitude and Information Questionnaire; SAS, Sexual Activity and Satisfaction Scale; SIS, Sexual Interest and Satisfaction Scale.

Table 2 Sexual health outcome measure reliability

\begin{tabular}{|c|c|c|c|c|c|}
\hline \multirow{2}{*}{ Outcome measure } & \multicolumn{2}{|c|}{ Internal consistency } & & \multicolumn{2}{|c|}{ Test-retest } \\
\hline & $\mathrm{n}$ & Cronbach's $\alpha$ & & Retest & Coefficient \\
\hline ERQ & - & - & - & - & - \\
\hline SAIQ & $\begin{array}{l}\text { Split-half reliability: } \\
\text { Split-half reliability: }\end{array}$ & $\begin{array}{l}r=0.68-0.81^{13} \\
r=0.47-0.90^{14}\end{array}$ & - & 2-3 weeks & $r=0.69-0.91$ \\
\hline SAS $^{13}$ & 75 & 0.87 & - & - & - \\
\hline SIS $^{16}$ & 73 & 0.96 & - & - & - \\
\hline
\end{tabular}

Abbreviations: EQR, Emotional Quality of the Relationship Scale; SAIQ, Sexual Attitude and Information Questionnaire; SAS, Sexual Activity and Satisfaction Scale; SIS, Sexual Interest and Satisfaction Scale; - , No data.

Table 3 Sexual health outcome measure validity

\begin{tabular}{|c|c|c|c|}
\hline Outcome measure & $\mathrm{n}$ & Convergent/divergent/known groups validity & Content validity \\
\hline $\mathrm{EQR}^{13}$ & 75 & $\begin{array}{l}\text { Sexual Activity and Satisfaction Scale } r=0.57 \\
\text { Sexual Behavior Scale } r=0.45 \\
\text { Hospital Anxiety and Depression Scale (HAD) } r=-0.38 \\
\text { Quality of life (VAS) } r=0.37\end{array}$ & - \\
\hline $\mathrm{SAIQ}^{14}$ & - & Old SCI ( $\geq 1$ year) vs new SCI ( $<1$ year): $t=1.79$ for Scale I only & $\begin{array}{l}\text { Interscale correlations: } \\
\text { III and IV } r=-0.44(n=34) \\
\text { III and O } r=-0.71(n=17)\end{array}$ \\
\hline $\mathrm{SAS}^{13}$ & 75 & $\begin{array}{l}\text { EQR } r=0.57 \\
\text { Sexual Behavior Scale, } r=0.85 \\
\text { HAD } r=-0.49 \\
\text { Quality of life (VAS) } r=0.39\end{array}$ & - \\
\hline SIS $^{16}$ & 73 & $\begin{array}{l}\text { Age of injury } r=0.63 \\
\text { Total QL rating } r=0.52 \\
\text { Dysfunction } r=-0.61 \\
\text { Depression } r=-0.45 \\
\text { Loss of independence } r=-0.49\end{array}$ & - \\
\hline
\end{tabular}

Abbreviations: EQR, Emotional Quality of the Relationship Scale; SAIQ, Sexual Attitude and Information Questionnaire; SAS, Sexual Activity and Satisfaction Scale; SIS, Sexual Interest and Satisfaction Scale; - , No data.

Table 4 Sexual health outcome measure responsiveness

\begin{tabular}{|c|c|c|c|}
\hline Outcome Measure & $\mathrm{n}$ & Method & Responsiveness \\
\hline EQR & - & - & - \\
\hline SAIQ $^{15}$ & 12 & $\begin{array}{l}\text { Mean change in rating score pre- and post-sexual education } \\
\text { and counseling program }\end{array}$ & $\begin{array}{l}\text { Sexual behavior acceptability ratings: } t=2.14, P<0.05 \\
\text { Concern about sexual function: } t=2.50, P<0.05\end{array}$ \\
\hline SAS & - & - & - \\
\hline SIS & - & - & - \\
\hline
\end{tabular}




\section{Discussion}

Although the four outcome measurement tools identified for this review have not been used extensively and are becoming outdated, they may have a purpose in SCI research and clinical practice. This is particularly true if the tools are used as originally intended as part of a larger measure or one of a number of investigative tools or techniques.

There are several limitations to the outcome measures reviewed. Viewed as stand-alone scales, or even within the context of broader research, none had the capacity to assess all the topics cited as relevant to persons with SCI or to ascertain the sexual health outcomes of this population. These tools are also limited in terms of the population they are meant to assess. Apart from the SAIQ, all the scales focused on partnered individuals, and therefore have no relevance to those who are not in a relationship. By limiting respondents to partnered individuals only, the tools do not allow for assessment of sexuality from solo sexual experiences; however, it is recognized that long term, trusted partnerships are integral to most persons successfully maximizing their sexual potential after injury. ${ }^{19}$ Furthermore, questioning focused on partnered activity misses the wealth of information available from self-experimentation. ${ }^{20}$ It is also not clear whether these tools have been tested in any population other than heterosexual. Indeed the mention of 'sexual intercourse' in one SAS $^{13}$ item leads to the conclusion that this tool may not be appropriate to use in any population other than partnered heterosexuals. To broaden this tools population scope, use of neutral terminology, such as 'sexual penetration' may be beneficial. Another limitation of these tools is the lack of concept definitions. For example, positive sexual adjustment for some may mean abstinence from sexual activity, whereas for others this would be perceived as negative sexual adjustment. Even the term 'sexual health' is not a static concept, but rather holds great subjectivity and may continue to evolve with time for both individuals and populations. ${ }^{21}$ As Mona et al. ${ }^{22}$ point out in their 2000 article, if terms are to be used as endpoints or outcomes, it is imperative that the terms are specifically defined. Because of the broad and fluid nature of these sexual terms, they may be interpreted very differently, by subjects and researchers alike, hence altering the meaning of the data collected.

Many tools are commonly used in sexual assessment SCI studies today, including the International Index of Erectile Function (IIEF) ${ }^{23-39}$ and the Female Sexual Function Index (FSFI), ${ }^{32,40,41}$ however, neither of these have been validated specifically for SCI. As with the reviewed outcome measures, the tools currently used also lack defined nomenclature to describe sexual aspects of functioning after SCI. ${ }^{42}$

\section{Recommendations}

Given the complex nature of sexual health, developing a validated tool in sexuality after SCI is challenging. As there is no clinically agreed upon measurement tool for determining the sexual health outcomes for persons with SCI, it is recommended that the sexual health outcome measures of the future will include both quantitative and qualitative data as well as address the following:

(1) Sexual health priorities for persons with SCI

(2) Consequences of SCI that indirectly affect sexuality (such as bladder, bowel, dysreflexia issues).

(3) Partnership status

(4) Sexual orientation

(5) Functional ability to participate sexually

\section{Summary}

A benchmark sexual health outcome measure is needed by SCI clinicians for use in both research and clinical practice. Evidence-based interventions could be developed using the tool. Ultimately, consistent best practices in sexual health care would result.

\section{Acknowledgements}

We thank ICORD and the GF Strong Rehabilitation Centre Sexual Health Rehab Service for their support.

\section{References}

1 Anderson KD. Targeting recovery: priorities of the spinal cordinjured population. J Neurotrauma 2004; 21: 1371-1383.

2 Anderson KD, Borisoff JF, Johnson RD, Stiens SA, Elliott SL. The impact of spinal cord injury on sexual function: concerns of the general population. Spinal Cord 2007; 45: 328-337.

3 Fisher TL, Laud PW, Byfield MG, Brown TT, Hayat MJ, Fiedler IG. Sexual health after spinal cord injury: a longitudinal study. Arch Phys Med Rehabil 2002; 83: 1043-1051.

4 Post MW, Van Dijk AJ, Van Asbeck FW, Schrijvers AJ. Life satisfaction of persons with spinal cord injury compared to a population group. Scand J Rehabil Med 1998; 30: 23.

5 White MJ, Rintala DH, Hart KA, Fuhrer MJ. Sexual activities, concerns and interests of women with spinal cord injury living in the community. Am J Phys Med Rehabil 1993; 72: 372-378.

6 White MJ, Rintala DH, Hart KA, Young ME, Fuhrer MJ. Sexual activities, concerns and interests of men with spinal cord injury. Am J Phys Med Rehabil 1992; 71: 225-231.

7 Westgren N, Hultling C, Levi R, Seiger A, Westgren M. Sexuality in women with traumatic spinal cord injury. Acta Obstet Gynecol Scand 1997; 76: 977-983.

8 Kennedy P, Lude P, Taylor N. Quality of life, social participation, appraisals and coping post spinal cord injury: a review of four community samples. Spinal Cord 2006; 44: 95-105.

9 Forsythe E, Horsewell JE. Sexual rehabilitation of women with a spinal cord injury. Spinal Cord 2006; 44: 234-241.

10 Leibowitz RQ. Sexual rehabilitation services after spinal cord injury: what do women want? Sex Disabil 2005; 23: 81.

11 Valtonen K, Karlsson AK, Siosteen A, Dahlof LG, Viikari-Juntura E. Satisfaction with sexual life among persons with traumatic spinal cord injury and meningomyelocoele. Disabil Rehabil 2006; 28: 965-976.

12 SCIRE Team. SCIRE: Spinal cord injury rehabilitation evidence. 2006; Available at: http://www.icord.org/scire/.

13 Kreuter M, Sullivan M, Siosteen A. Sexual adjustment and quality of relationship in spinal paraplegia: a controlled study. Arch Phys Med Rehabil 1996; 77: 541-548.

14 Brockway J, Steger JC. Sexual attitude and information questionnaire: reliability and validity in a spinal cord injured population. Sex Disabil 1981; 4: 49. 
15 Brockway J, Steger JC, Berni R, Ost VV, Williamson-Kirkland TE, Peck CL. Effectiveness of a sex education and counseling program for spinal cord injured patients. Sex Disabil 1978; 1: 127-136.

16 Siosteen A, Lundqvist C, Blomstrand C, Sullivan L, Sullivan M. Sexual ability, activity, attitudes and satisfaction as part of adjustment in spinal cord-injured subjects. Paraplegia 1990; 28: 285-295.

17 Kendall M, Booth S, Fronek P, Miller D, Geraghty T. The development of a scale to assess the training needs of professionals in providing sexuality rehabilitation following spinal cord injury. Sex Disabil 2003; 21: 49-64.

18 Kreuter M, Sullivan M, Siosteen A. Sexual adjustment after spinal cord injury (SCI) focusing on partner experiences. Paraplegia 1994; 32: 225-235.

19 Tepper MS. Lived experiences that impede or facilitate sexual pleasure and orgasm in people with spinal cord injury. Doctoral Thesis, University of Pennsylvania 2001.

20 Elliott S. Sexual dysfunction and infertility in men with spinal cord disorders. In: Lin V (ed). Spinal Cord Medicine: Principles and Practice. Demos Medical Publishing: New York, 2003 pp 349-365.

21 Edwards WM, Coleman E. Defining sexual health: a descriptive overview. Arch Sex Behav 2004; 33: 189-195.

22 Mona LR, Krause JS, Norris FH, Cameron RP, Kalichman SC, Lesondak LM. Sexual expression following spinal cord injury. NeuroRehabilitation 2000; 15: 121-131.

23 Cardenas DD, Ditunno J, Graziani V, Jackson AB, Lammertse D, Potter $\mathrm{P}$ et al. Phase 2 trial of sustained-release fampridine in chronic spinal cord injury. Spinal Cord 2007; 45: 158-168.

24 Del Popolo G, Li Marzi V, Mondaini N, Lombardi G. Time/ duration effectiveness of sildenafil versus tadalafil in the treatment of erectile dysfunction in male spinal cord-injured patients. Spinal Cord 2004; 42: 643-648.

25 Gans WH, Zaslau S, Wheeler S, Galea G, Vapnek JM. Efficacy and safety of oral sildenafil in men with erectile dysfunction and spinal cord injury. J Spinal Cord Med 2001; 24: 35-40.

26 Giuliano F, Hultling C, El Masry WS, Smith MD, Osterloh IH, Orr $\mathrm{M}$ et al. Randomized trial of sildenafil for the treatment of erectile dysfunction in spinal cord injury. Sildenafil Study Group. Ann Neurol 1999; 46: 15-21.

27 Giuliano F, Rubio-Aurioles E, Kennelly M, Montorsi F, Kim ED, Finkbeiner AE et al. Efficacy and safety of vardenafil in men with erectile dysfunction caused by spinal cord injury. Neurology 2006; 66: 210-216.

28 Goldstein I, Kim E, Steers WD, Pryor JL, Wilde DW, Natanegara F et al. Efficacy and safety of tadalafil in men with erectile dysfunction with a high prevalence of comorbid conditions: results from MOMENTUS: multiple observations in men with erectile dysfunction in National Tadalafil Study in the US. J Sex Med 2007; 4: 166-175.
29 Hultling C, Giuliano F, Quirk F, Pena B, Mishra A, Smith MD. Quality of life in patients with spinal cord injury receiving Viagra (sildenafil citrate) for the treatment of erectile dysfunction. Spinal Cord 2000; 38: 363-370.

30 Kimoto Y, Sakamoto S, Fujikawa K, Tachibana T, Yamamoto N, Otani T. Up-titration of vardena fi 1 dose from 10 to $20 \mathrm{mg}$ improved erectile function in men with spinal cord injury. Int $J$ Urol 2006; 13: 1428-1433.

$31 \mathrm{Ku} \mathrm{JH}$, Oh SJ, Jeon HG, Shin HI, Paik NJ, Yoo T et al. Sexual activity in Korean male patients on clean intermittent catheterization with neurogenic bladder due to spinal cord injury. Int $J$ Urol 2006; 13: 42-46.

32 Lombardi G, Mondaini N, Iazzetta P, Macchiarella A, Popolo GD. Sexuality in patients with spinal cord injuries due to attempted suicide. Spinal Cord; e-pub ahead of print: 10 April 2007.

33 Morgentaler A, Barada J, Niederberger C, Donatucci C, Garcia CS, Natanegara $\mathrm{F}$ et al. Efficacy and safety of tadalafil across ethnic groups and various risk factors in men with erectile dysfunction: use of a novel noninferiority study design. J Sex Med 2006; 3: 492-503.

34 Sanchez Ramos A, Vidal J, Jauregui ML, Barrera M, Recio C, Giner M et al. Efficacy, safety and predictive factors of therapeutic success with sildenafil for erectile dysfunction in patients with different spinal cord injuries. Spinal Cord 2001; 39: 637-643.

35 Schmid DM, Schurch B, Hauri D. Sildenafil in the treatment of sexual dysfunction in spinal cord-injured male patients. Eur Urol 2000; 38: 184-193.

36 Sipski M, Alexander CJ, Gomez-Marin O. Effects of level and degree of spinal cord injury on male orgasm. Spinal Cord 2006; 44: 798-804.

37 Soler JM, Previnaire JG, Denys P, Chartier-Kastler E. Phosphodiesterase inhibitors in the treatment of erectile dysfunction in spinal cord-injured men. Spinal Cord 2007; 45: 169-173.

38 Strebel RT, Reitz A, Tenti G, Curt A, Hauri D, Schurch B. Apomorphine sublingual as primary or secondary treatment for erectile dysfunction in patients with spinal cord injury. BJU Int 2004; 93: 100-104.

39 Suh DD, Yang CC, Clowers DE. Nocturnal penile tumescence and effects of complete spinal cord injury: possible physiologic mechanisms. Urology 2003; 61: 184-189.

40 Lombardi G, Mondaini N, Macchiarella A, Del Popolo G. Female sexual dysfunction and hormonal status in spinal cord injured (SCI) patients. J Androl 2007; 28: 722-726.

41 Matzaroglou C, Assimakopoulos K, Panagiotopoulos E, Kasimatis G, Dimakopoulos P, Lambiris E. Sexual function in females with severe cervical spinal cord injuries: a controlled study with the Female Sexual Function Index. Int J Rehabil Res 2005; 28: 375-377.

42 Alexander MS, Bodner D, Brackett NL, Elliott S, Jackson AB, Sonksen J. Development of international standards to document sexual and reproductive functions after spinal cord injury: Preliminary report. J Rehabil Res Dev 2007; 44: 83. 